Check for updates

Cite this: RSC Adv., 2017, 7, 26458

Received 22nd March 2017

Accepted 3rd May 2017

DOI: $10.1039 / c 7 r a 03354 k$

rsc.li/rsc-advances

\section{Effect of acetone extract from natural rubber on the structure and interface interaction in NR/CB composites}

\author{
Tiwen $\mathrm{Xu}^{\mathrm{a}}$ Zhixin Jia, (D) ${ }^{* a}$ Lianghui Wu, ${ }^{a}$ Yongjun Chen, ${ }^{a}$ Yuanfang Luo, ${ }^{a}$ Demin $\mathrm{Jia}^{a}$ \\ and Zheng Peng ${ }^{b}$
}

\begin{abstract}
The influences of acetone extract (AE) from natural rubber on the interface structure of NR/CB composites were investigated through rubber process analyzer (RPA), scanning electron microscopy (SEM), Raman spectroscopy, X-ray diffraction (XRD), and differential scanning calorimetry (DSC). The results demonstrated that the crystallite size of $\mathrm{CB}$ was increased by $\mathrm{AE}$, leading to the decrease of dispersive free energy $\left(\gamma_{s}^{d}\right)$ on the $C B$ surface, which results in a reduction of CB-NR interaction. Oppositely, AE also increased the number of physical entanglement points in NR/CB matrix for its polarity interaction with $\mathrm{CB}$, which could promote the $\mathrm{CB}-\mathrm{NR}$ interaction. Consequently, the optimized value of $\mathrm{AE}$ in NR/ $C B$ matrix is 2 phr, where the optimal mechanical and dynamical properties were obtained. Simultaneously, AE had a negative effect on the strain-induced crystallization behaviors of NR/CB composites. This research may draw attention to the evaluation of quality standards of NR.
\end{abstract}

\section{Introduction}

Natural rubber is collected from Hevea brasiliensis and is widely used in the industry. For its natural distinction, NR is actually a mixture of compounds, consisting of cis-1,4-polyisoprene (95\% w/ $\mathrm{w})$ and non-isoprene compounds as proteins $(1-2 \% \mathrm{w} / \mathrm{w})$, acetone extract $(1-2 \% \mathrm{w} / \mathrm{w})$, carbohydrates $(0.4 \% \mathrm{w} / \mathrm{w})$ and minerals $(0.3-$ $0.7 \% \mathrm{w} / \mathrm{w}){ }^{1}$ All of these are affected by climate, territory, breed or process conditions. These non-isoprene compounds are important to the stability of natural rubber latex, rubber processability, and even the mechanical properties ${ }^{2-6}$ of the vulcanizate. Unfortunately, the critical components of non-isoprene compounds are still unclear, let alone the effect of these factors on the natural rubber network structure and application performance. In fact, NR is often applied with inorganic particles, such as carbon black, silica, ${ }^{7}$ MMT, ${ }^{8}$ and HNTs, ${ }^{9}$ which is more valuable to practice. However, few researchers were concerned about the influence of non-isoprene compounds on the mechanical and dynamical properties or interface structure of filled NR composites.

Acetone extract $(\mathrm{AE})$, as one of the non-isoprene compounds, is important to the quality of NR. It consists of oleic acid, linoleic acid, stearic acid, and sterol ester, as reported..$^{10}$ Researchers reported that some accelerants and sterol antioxidant contained in $\mathrm{AE}$ could positively affect the curing rate and anti-aging resistance to ozone ${ }^{11-13}$ of unfilled natural rubber. Carbon black, as

${ }^{a}$ College of Materials Science and Engineering, South China University of Technology, Guangzhou 510640, China. E-mail: 18620901980m@sina.cn; Tel: +862087114857

${ }^{b}$ Agricultural Product Processing Research Institute, Chinese Academy of Tropical Agriculture Sciences, Zhanjiang 524001, China a common filler, is widely used in natural rubber composites. W. Thongruang $^{14}$ explored the correlations of electrical and mechanical properties of NR/CB composites, focusing on differences in mixing methods, curing ingredients or sample thickness. $\mathrm{Xu}^{15}$ investigated the influence of $\mathrm{CB}$ grafted with degraded natural rubber on the mechanical and dynamical properties of NR/CB composites, which performed well on tensile stress and tear strength. Others reports about the influence of filler types ${ }^{16}$ or hybrid filler ${ }^{17}$ on the properties of NR/CB composites were also done. Above all, researchers payed close attention to the modification of $\mathrm{CB}$ particles, and preparation methods that could significantly improve the performance of NR/CB composites. No reports were published about the effects of $\mathrm{AE}$ on the dynamical and mechanical properties or structure variation of $\mathrm{NR} / \mathrm{CB}$ composites, which are valuable to the application of NR in tyres.

In this study, NR/CB composites with different $\mathrm{AE}$ were prepared on double rolls open mill. The structural variations of $\mathrm{CB}$ and composites caused by $\mathrm{AE}$ were investigated through Raman spectroscopy, XRD, DSC and stress-strain behaviors. Simultaneously, the mechanical and dynamic properties of composites and CB-rubber interaction were also illustrated. The results clarified the impact of $\mathrm{AE}$ on the structure and dynamic properties of $\mathrm{NR} / \mathrm{CB}$ composites, which could offer valuable information on Hevea brasiliensis cultivation and on the application of $\mathrm{NR} / \mathrm{CB}$ composites.

\section{Experimental}

\section{Materials}

Natural rubber (NR), with trade name SCR-WF, was supplied by Hainan Sinochem Rubber Company, Ltd (Hainan, China). 
Carbon black (CB N330) was purchased from Guangzhou Institute of Rubber Industry Products Co., Ltd (Guangdong, China). DBP was determined to be $103 \times 10^{-5} \mathrm{~m}^{3} \mathrm{~kg}^{-1}$. Other ingredients are commercially industrial products and used as received.

\section{Preparation of NR/CB composites modified by AE}

First, natural rubber was extracted by acetone for $48 \mathrm{~h}$ through the Soxhlet extraction method and the residual solution was concentrated using a rotary evaporator to obtain the acetone extract (AE). The dried natural rubber NR was mixed with other ingredients on a X(S)K-160 open-mill (Dongguan, China) at room temperature. Basic formulation (mass parts): NR 100, CB (0 or 30$)$, AE (0-5), zinc oxide 5 , stearic acid 2 , sulfur $1.5, \mathrm{~N}$ cyclohexyl-2-benzothiazolesulfenamide (accelerator CZ) 1.5, benzothiazole disulfide (accelerator DM) 0.5. The optimum curing time $\left(T_{90}\right)$ was determined at $143{ }^{\circ} \mathrm{C}$ by a UR-2030 oscillating disk rheometer (U-CAN Technology Company, Ltd, Taiwan). The compounds were vulcanized on a KSH R100 flat vulcanizing machine (Kesheng Machinery Co., Ltd, Dongguan, China) after their accommodation at room temperature for $4 \mathrm{~h}$.

\section{Preparation of NR/CB/AE model compound}

$\mathrm{NR} / \mathrm{CB} / \mathrm{AE}$ and NR/CB model compounds with the mass ratios of 100/30/5 and 100/30, respectively, were made on a X(S)K-160 open-mill at room temperature for $10 \mathrm{~min}$. No additives were used in this experiment. Then, the compounds were extracted in a Soxhlet extractor using acetone for $72 \mathrm{~h}$, to eliminate the free-moving components of $\mathrm{AE}$, and then extracted by toluene for $72 \mathrm{~h}$ continuously, to remove the weakly adsorbed NR molecules from CB. The residuum after extraction was analyzed through Raman spectroscopy and XRD to investigate the interaction.

\section{Analysis and characterization}

Strain sweeps of unvulcanized NR/CB composites were conducted by Rubber Processing Analyzer (RPA) (RPA 2000, Alpha, USA) from $0.7 \%$ to $200 \%$ at $100{ }^{\circ} \mathrm{C}, 1 \mathrm{~Hz}$. The morphology of fractured surfaces of vulcanized NR/CB composites $(15 \mathrm{~mm} \times 6$ $\mathrm{mm} \times 1 \mathrm{~mm}$ ) was observed using a ZEISS Merlin SEM (EVO18 German) machine at an acceleration voltage of $10.0 \mathrm{kV}$. Tensile properties and tear strength of vulcanizates were determined according to ISO 37-2005 standard (dumbbell A shape) and ISO 34-1:2004 (nicked angle), respectively, at $25{ }^{\circ} \mathrm{C}$ using a U-CAN UT-2060 instrument. Shore A hardness was performed following ISO 7619-1:2004 using a XY-1 durometer (Shanghai). Rolling resistance of composites was obtained via a RSS-II rolling resistance testing machine (Beijing Wan Hui Technology Development Co., Ltd, China). Compression fatigue heat production of composites was determined by a RH-2000N (GOTECH Testing Machines Inc.) compression fatigue tester according to ISO4666/3-1982. Abrasion resistance of vulcanized composites was determined using a rotating cylindrical drum device (DIN) according to ISO 4649:2002. Raman spectrum was implemented by a DXR (American Thermo Electron) Laser Cofocal Microscopy Raman Spectrometer in the range of 100-
$3000 \mathrm{~cm}^{-1}$ at a wavelength of $523 \mathrm{~nm}$. XRD spectrum was recorded on a X' Pert PRO (PANalytical, Holland) wide angle Xray diffraction system, using $\mathrm{Cu} \mathrm{K} \alpha$ radiation $(\lambda=0.154 \mathrm{~nm})$ with a diffraction angle of $5-90^{\circ}$ at a step order of $0.017^{\circ}$ per $16.24 \mathrm{~s}$.

The glass transition behaviors of NR/CB composites were examined on a NETZSCH DSC $204 \mathrm{~F}$ machine. The temperature program involved a $5 \mathrm{~min}$ isothermal hold at $-80{ }^{\circ} \mathrm{C}$, followed by heating at $3{ }^{\circ} \mathrm{C} \mathrm{min}^{-1}$ to $10{ }^{\circ} \mathrm{C}$ under nitrogen. The heat capacity step, $\Delta C_{\mathrm{pn}}$, and weight fraction of immobilized polymer layer, $\chi_{\mathrm{im}}{ }^{1 \mathbf{1 8 1 9}}$ were calculated as follows:

$$
\begin{gathered}
\Delta C_{\mathrm{pn}}=\Delta C_{\mathrm{p}} /(1-w) \\
\chi_{\mathrm{im}}=\left(\Delta C_{\mathrm{p} 0}-\Delta C_{\mathrm{pn}}\right) / \Delta C_{\mathrm{p} 0}
\end{gathered}
$$

where $\Delta C_{\mathrm{p}}$ is the heat capacity jump at $T_{\mathrm{g}} . \Delta C_{\mathrm{pn}}$ is normalized to the polymer weight fraction. $w$ is the weight fraction of filler. $\Delta C_{\mathrm{p} 0}$ refers to the heat capacity jump at $T_{\mathrm{g}}$ of the unfilled polymer matrix. $\chi_{\mathrm{im}}$ is the weight fraction of immobilized polymer layer. $T_{\mathrm{g}}$ was determined according to ASTM E1356-08, and $\Delta C_{\mathrm{p}}$ was calculated using the NETZSCH Thermal Analysis software.

\section{Results and discussion}

\section{Effect of $A E$ on the dispersion of $\mathrm{CB}$ in NR/CB composites}

Fig. 1 depicts the RPA strain sweep plots of unvulcanized NR/CB composites with different AE. It can be seen that shear modulus $\left(G^{\prime}\right)$ is increased by increasing AE until it obtains a threshold value at $4 \mathrm{phr} \mathrm{AE}$. The result illustrates that the Payne effect of NR/CB composites was enhanced via adding AE. Normally, $G^{\prime}$ decreases along with an increase in strain, which is called the Payne effect; a high value of $G^{\prime}$ at low strain presents a great degree of aggregation of filler network that would deduce a poor mechanical performance of composites. To further investigate the dispersion of $\mathrm{CB}$ in NR matrix, SEM images of NR/CB composites were obtained, which are displayed in Fig. 2. It can be seen that there are no CB aggregates in NR matrix except those shown in Fig. 2(f). Therefore, the enhancement of the

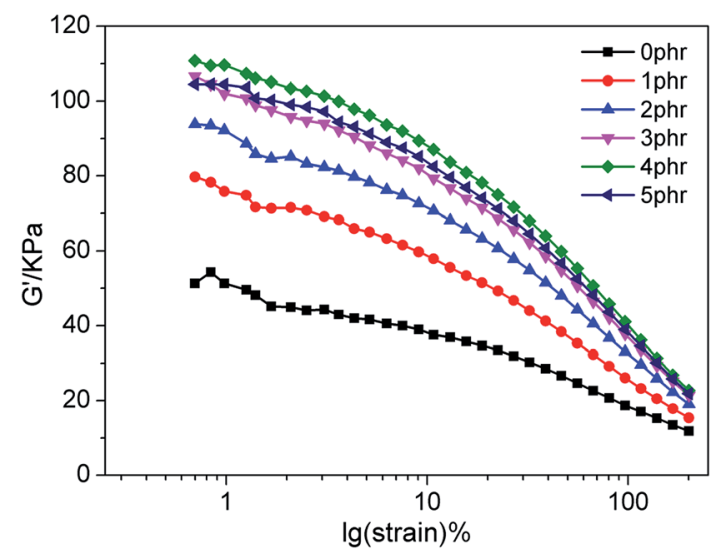

Fig. 1 RPA strain sweep of unvulcanized NR/CB composites with different contents of $\mathrm{AE}$. 

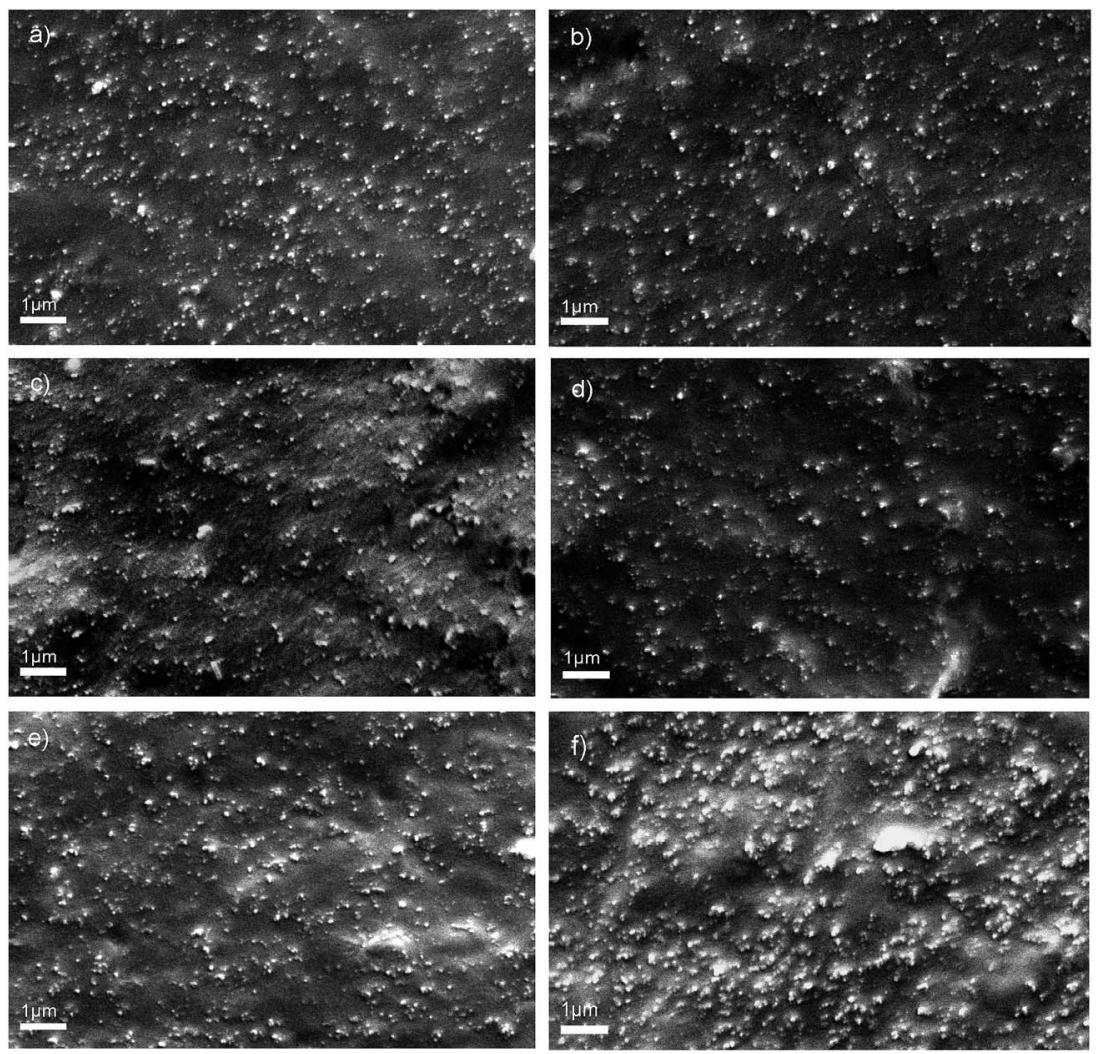

Fig. 2 SEM images of brittle fracture surfaces of vulcanized NR/CB composites with different AE contents: (a) 0 phr, (b) 1 phr, (c) 2 phr, (d) 3 phr, (e) 4 phr, (f) 5 phr.

Payne effect could not have been caused by the aggregation of CB. This phenomenon could be interpreted through chain entanglement theory. After extraction treatment by acetone, physical entanglement points of natural rubber were destroyed and then replaced by $\mathrm{CB}$ particles when preparing $\mathrm{NR} / \mathrm{CB}$ composites. Due to the alkyl and oxygen-containing groups structure ${ }^{10}$ of $\mathrm{AE}$ components, $\mathrm{CB}$ could migrate more easily in the $\mathrm{NR} / \mathrm{CB} / \mathrm{AE}$ system than that of unmodified composites to form a large number of new entanglement points, leading to the enhancement of $G^{\prime}$ of composites at low strain. Simultaneously, the decrease of $G^{\prime}$ on $5 \mathrm{phr}$ loading should be attributed to the plasticizing effects of small molecular substances of AE.

\section{Analysis of constrained regions of composites by DSC}

It is well known that glass transition behavior is a typical feature of polymer molecules that can offer structural variation information of polymers. Normally, $T_{\mathrm{g}}$ and normalized change of heat capacity $\left(\Delta C_{\mathrm{p}}\right)$ of a polymer at the glass transition region are used to evaluate the mobility of polymer molecules that are sensitive to the local environment. ${ }^{20}$ Fig. 3 shows the glass transition behaviors of unfilled NR and NR/CB composites with different AE.

As can be seen, $T_{\mathrm{g}}$ parameters of all samples exhibit no systematic variation upon changing the composition, which is in line with other reports. ${ }^{21,22}$ One reason for this is that the average size of immobilized polymer region is greater than the length scale of segmental motion and the relaxation is independent of the composition. ${ }^{23}$ The other is the plasticization effect ${ }^{24}$ caused by $\mathrm{AE}$ that might promote the mobility of the molecular chain. The normalized heat capacity $\left(\Delta C_{\mathrm{pn}}\right)$ is proportional to the number of internal degrees of freedom of molecular motion and could represent the change of polymer chain mobility in the composites directly. ${ }^{20,25}$ The greater value of $\Delta C_{\mathrm{pn}}$ at the glass transition region indicates a better chain mobility. In Fig. $3, \Delta C_{\mathrm{pn}}$ is increased via increasing $\mathrm{AE}$ in $\mathrm{NR} / \mathrm{CB}$

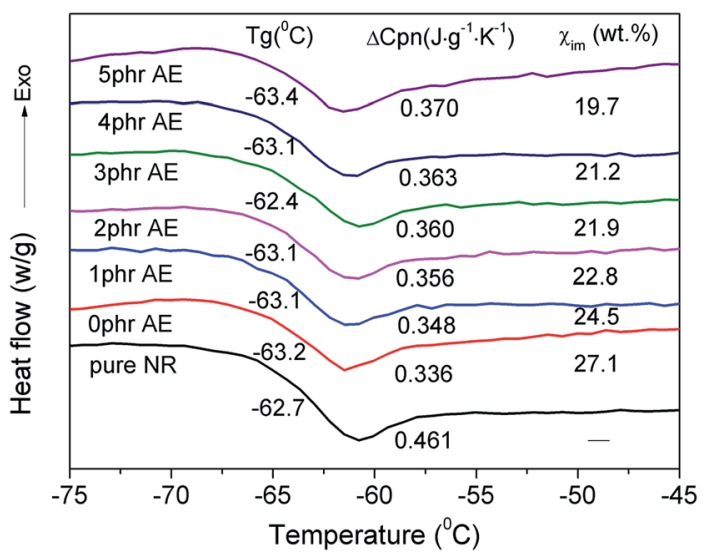

Fig. 3 Glass transition behaviors of NR/CB composites with different contents of $\mathrm{AE}$. 

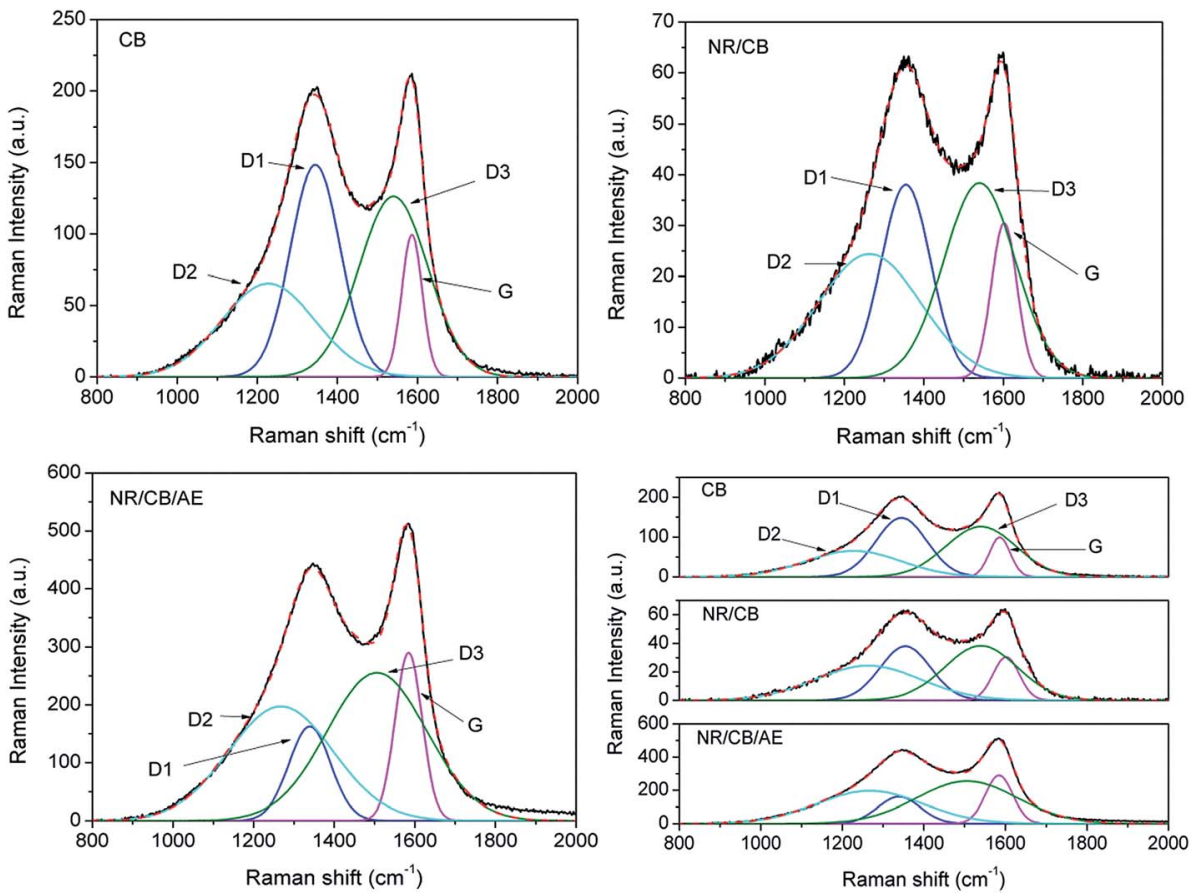

Fig. 4 Raman spectra peak fitting of pure $C B$, residual $C B$ from extracted NR/CB and NR/CB/AE model compounds.

composites, which indicates improved mobility of the rubber chain. Thus, a reduction of constrained regions is achieved through the decline of weight fraction of immobilized polymer layer $\left(\chi_{\mathrm{im}}\right)$ directly. Synthetically, AE might give a negative effect on filler-rubber interaction in NR/CB matrix, particularly with a high loading content.

\section{Raman spectrum}

Raman spectroscopy is sensitive to short range disorder and it can reveal the microstructure of CB for its activity toward C-C single bond. ${ }^{26} \mathrm{~A}$ previous report ${ }^{27}$ indicated the importance of Raman spectrum on surface characterization of partially ordered carbon materials. As we know, CB consists of agglomerated spherical primary particles and exists in a wide range of ordered and disordered regions, also called graphite crystalline regions and amorphous areas. ${ }^{28}$ To further investigate the influence of $\mathrm{AE}$ on the microstructure of $\mathrm{CB}$, Raman spectrum was employed and the spectral information of pure $\mathrm{CB}$ and residual $\mathrm{CB}$ from extracted $\mathrm{NR} / \mathrm{CB}$ and $\mathrm{NR} / \mathrm{CB} / \mathrm{AE}$ model compounds is presented in Fig. 4 . It can be seen that two relatively broad bands appear in the range of 1000-1800 $\mathrm{cm}^{-1}$ : the former at $\sim 1350 \mathrm{~cm}^{-1}$ is $\mathrm{D}$ band is typical of the structural disorder and defects, and the latter at $\sim 1580 \mathrm{~cm}^{-1}$ is $\mathrm{G}$ band for the typical graphitic order. ${ }^{27}$ Generally, the variation information of CB microstructure is much more significant in NR matrix without AE for its larger Raman shift compared with pure CB spectrum. This might be evidence of the weakened interaction between $\mathrm{CB}$ and the rubber phase caused by $\mathrm{AE}$.

In order to improve the accuracy in the determination of spectroscopic parameters, such as peak position, bandwidth, lineshape and band intensity, mixed Gaussian-Lorentzian curve fitting ${ }^{26,29}$ was carried out for each spectrum. Good fits are obtained in Fig. 4, and the data are shown in Table 1. The degree of disorder of D1 is lower than D2 or D3. The definition in article is in line with other report. ${ }^{28}$ Compared with the parameters of pure CB, the D1 band of CB shifts from 1345 $\mathrm{cm}^{-1}$ to $1355 \mathrm{~cm}^{-1}$ in the NR/CB system, in contrast with 1339 $\mathrm{cm}^{-1}$ in the NR/CB/AE system. $\mathrm{G}$ band of $\mathrm{CB}$ appears to have a larger variation for the NR/CB system than that of the NR/CB/ AE system. Simultaneously, the bandwidth of D1 mode is significantly narrower than that of pure $\mathrm{CB}$, confirming that the degree of ordering of $\mathrm{CB}$ in the $\mathrm{NR} / \mathrm{CB} / \mathrm{AE}$ system is greater than that of pure CB. ${ }^{26}$ Contrasting with the D1 bandwidth of CB in

Table 1 Raman spectroscopic parameters of $C B$, residual $C B$ from extracted NR/CB and NR/CB/AE model compounds obtained after curve fitting the experimental spectra by using two Lorentzian bands (D1 and G) and two Gaussian bands (D2 and D3)

\begin{tabular}{llllll}
\hline Sample & & $\begin{array}{l}\text { Peak position } \\
\nu\left(\mathrm{cm}^{-1}\right)\end{array}$ & $\begin{array}{l}\text { Bandwidth } \\
\omega_{1 / 2}\left(\mathrm{~cm}^{-1}\right)\end{array}$ & $\begin{array}{l}\text { Intensity } \\
(\text { peak area\%) }\end{array}$ & $\begin{array}{l}L_{\mathrm{a}} \\
(\mathrm{nm})\end{array}$ \\
\hline $\mathrm{CB}$ & D1 & 1345 & 147 & 31 & 1.1 \\
& D2 & 1228 & 273 & 25 & \\
& D3 & 1540 & 204 & 36 & \\
& G & 1586 & 60 & 8 & 1.8 \\
$\mathrm{NR} / \mathrm{CB}$ & D1 & 1355 & 146 & 24 & \\
& D2 & 1263 & 304 & 32 & \\
& D3 & 1540 & 211 & 34 & \\
$\mathrm{NR} / \mathrm{CB} /$ & $\mathrm{G}$ & 1602 & 76 & 10 & \\
$\mathrm{AE}$ & $\mathrm{D} 1$ & 1339 & 122 & 11 & \\
& D2 & 1268 & 306 & 34 & \\
& D3 & 1506 & 291 & 42 & \\
& $\mathrm{G}$ & 1585 & 79 & 13 &
\end{tabular}


the NR/CB system, it indicates that AE could increase the degree of ordering of CB. Normally, G mode is related to the crystalline component in carbons, and an increase of order in carbonaceous materials is reflected by a decrease of its bandwidth. However, the comparative study of the bandwidth of $\mathrm{G}$ mode does not allow conclusive remarks mentioned above. This might be due to the fact that D3 mode, which usually appears at $\sim 1620 \mathrm{~cm}^{-1}$ as a shoulder, is not observed in these four spectra and interferes with the $G$ mode, thus complicating the interpretation. ${ }^{26,30}$

The nanoscale crystal on the CB surface, proven by High Resolution Transmission Electron Microscopy (HRTEM), ${ }^{31}$ is important and its size, called microcrystalline planar crystal size $\left(L_{\mathrm{a}}\right)$, has a negative relationship to the dispersive free energy $\left(\gamma_{\mathrm{s}}^{\mathrm{d}}\right)^{32}$ of the CB surface. It is well known that $\gamma_{\mathrm{s}}^{\mathrm{d}}$ is the nonpolar part of CB surface free energy, and it presents a positive effect on the ability of CB to absorb the rubber macromolecule. Thus, $L_{\mathrm{a}}$ could be a direct evidence reflecting the adsorbability of CB on the rubber macromolecule. The larger its value, the weaker is its adsorption capacity on the rubber phase, as well as a weakened interaction between $\mathrm{CB}$ and rubber phase. $L_{\mathrm{a}}$ could be calculated from the following empirical formula: $L_{\mathrm{a}}=4.4 I_{\mathrm{G}} /$ $I_{\mathrm{D}},{ }^{26,28,32}$ where $I_{\mathrm{G}}$ and $I_{\mathrm{D}}$ are the integrated intensities of the $\mathrm{G}$ and D1 bands, respectively. It can be seen that $L_{\mathrm{a}}$ is increased from $1.1 \mathrm{~nm}$ of pure $\mathrm{CB}$ to $5.2 \mathrm{~nm}$ of the NR/CB/AE system, compared with $1.8 \mathrm{~nm}$ of the NR/CB system. This means that $\mathrm{AE}$ causes a significant decline in $\gamma_{\mathrm{s}}^{\mathrm{d}}$ of $\mathrm{CB}$ that induces the reduction of CB-NR interaction. The increase of $L_{\mathrm{a}}$ would lead to the diminution of quality and total area of grain boundary, both of which could cause the decrease of high-energy parts on the CB surface.

\section{XRD spectrum}

It was reported that carbon black is a heterogeneous mixture of particles that range from single graphite lavers up to graphite crystals several layers thick. ${ }^{33}$ The effective method to investigate the microstructure of $\mathrm{CB}$ particles is X-ray diffraction (XRD). ${ }^{34-36}$ Fig. 5 demonstrates the XRD spectra of $\mathrm{CB}$, residual CB from extracted NR/CB and NR/CB/AE model compounds. It can be seen in Fig. 5(a) that the 002 peak and
110 peak appear around $25^{\circ}$ and $44^{\circ}$, respectively, ${ }^{35,37}$ which are assigned according to the standard XRD spectrum of graphite. In contrast to the spectrum of pure $\mathrm{CB}$, the shapes and positions of diffraction peaks of residual $\mathrm{CB}$ from extracted $\mathrm{NR} / \mathrm{CB}$ and $\mathrm{NR} / \mathrm{CB} / \mathrm{AE}$ systems significantly changed. This indicates that a significant variation in the microstructure of $\mathrm{CB}$ appears via mixing of $\mathrm{CB}$ and NR, or adding AE into NR/CB compound.

To further study the variation of crystallites structure of $\mathrm{CB}$ in three different conditions, a Gaussian peak fitting program was employed; the results are shown in Fig. 5(b) and the data parameters are listed in Table 2. According to the theory of $\mathrm{J}$. Biscoe, ${ }^{32,34,35}$ crystallite plane size $H_{\mathrm{a}}$ (110 band) and crystallite axial size $H_{\mathrm{c}}$ (002 band) can be calculated by eqn (3) and (4):

$$
\begin{aligned}
& H_{\mathrm{a}}=\frac{1.84 \lambda}{B \cos \theta} \\
& H_{\mathrm{c}}=\frac{0.89 \lambda}{B \cos \theta}
\end{aligned}
$$

where $\lambda$ is the wavelength of the incident X-ray. $B$ is the width of half maximum intensity. $\theta$ is the Bragg angle (half of the scattering angle). $B$ and $\theta$ must be converted into radians during calculation. As is illustrated, $H_{\mathrm{a}}$ is increased from $1.87 \mathrm{~nm}$ of pure $\mathrm{CB}$ to $2.39 \mathrm{~nm}$ of the $\mathrm{NR} / \mathrm{CB}$ system, and it further

Table 2 XRD parameters of $C B$, residual $C B$ from extracted NR/CB and NR/CB/AE model compounds obtained after curve fitting by Gaussian bands

\begin{tabular}{llrlll}
\hline Sample & Peak & $B\left(^{\circ}\right)$ & $2 \theta\left(^{\circ}\right)$ & $H_{\mathrm{a}}(\mathrm{nm})$ & $H_{\mathrm{c}}(\mathrm{nm})$ \\
\hline $\mathrm{CB}$ & 002 & 6.72 & 24.27 & - & 1.20 \\
& 110 & 9.64 & 44.22 & 1.87 & - \\
$\mathrm{NR} / \mathrm{CB}$ & - & 7.65 & 19.22 & - & - \\
& 002 & 1.14 & 22.55 & - & 6.99 \\
& - & 5.40 & 24.79 & - & - \\
& 110 & 7.52 & 44.38 & 2.39 & - \\
$\mathrm{NR} / \mathrm{CB} / \mathrm{AE}$ & - & 12.77 & 21.82 & - & - \\
& 002 & 4.87 & 25.08 & - & 1.65 \\
& 110 & 5.41 & 43.15 & 3.31 & - \\
& - & 17.45 & 47.09 & - & - \\
& - & 8.37 & 79.88 & - & -
\end{tabular}
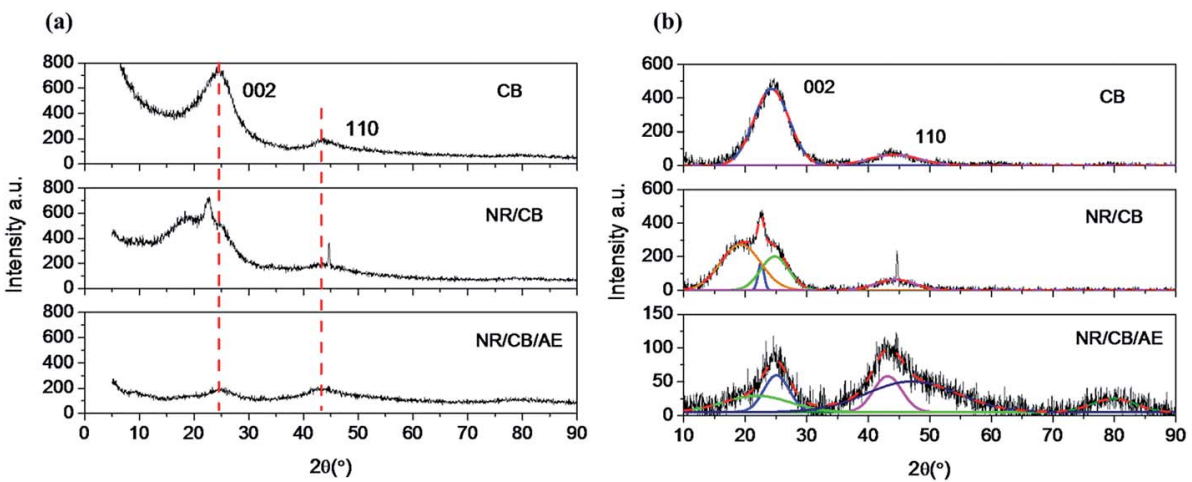

Fig. 5 XRD spectra of $C B$, residual CB from extracted NR/CB and NR/CB/AE model compounds: (a) original curves, (b) peak fitting through Gaussian curves. 
increases to $3.31 \mathrm{~nm}$ when $\mathrm{AE}$ is added. Simultaneously, $H_{\mathrm{c}}$ is also increased in the $\mathrm{NR} / \mathrm{CB}$ or the $\mathrm{NR} / \mathrm{CB} / \mathrm{AE}$ system compared with that of pure $\mathrm{CB}$, and the largest value is obtained without AE. Experimentally, $H_{\mathrm{a}}$ plays a negative role on the dispersive free energy $\left(\gamma_{\mathrm{s}}^{\mathrm{d}}\right)$ of the CB surface, where a large value of $H_{\mathrm{a}}$ implies a small value of $\gamma_{\mathrm{s}}^{\mathrm{d}}$. In addition, there is no remarkable relationship between $H_{\mathrm{c}}$ and $\gamma_{\mathrm{s}}^{\mathrm{d}}{ }^{32}$ Therefore, the increase of $H_{\mathrm{a}}$ by $\mathrm{AE}$ indicates a decline of $\gamma_{\mathrm{s}}^{\mathrm{d}}$, which induces the formation of weakened CB-rubber interaction. The result agrees with those of Raman spectra analysis and the bound rubber test. Generally, the critical parts that influence $\gamma_{\mathrm{s}}^{\mathrm{d}}$ are the small crystallites or faulty crystallites that result in numerous high energy parts where crystal boundary and defects exist, leading to the increase of $\gamma_{\mathrm{s}}^{\mathrm{d}}{ }^{38-40}$

\section{Effects of AE on strain-induced crystallization behaviors of NR/CB composites}

It is well known that NR is amorphous under the quiescent condition, but highly crystallizable upon stretching. XRD spectra of NR/CB composites at constant strain ratios $(\lambda)$ are presented in Fig. 6 . The 200 band and 120 band both reflect the change of crystallinity on the lateral direction, ${ }^{\mathbf{4 1}}$ which is perpendicular to the stretching orientation. It can be seen that crystallization behaviors show up at $\lambda=3$ for all specimens and these could be enhanced while increasing the strain sequentially. However, there is no significant difference observed in the curves with different AE.
In order to reveal the structural variation of $\mathrm{NR} / \mathrm{CB}$ composites clearly, a peak fitting program was employed using Origin software and Gaussian bands of XRD curves in the range of $10-30^{\circ}$ are described in Fig. 7. All the samples with different AE display four Gaussian bands at $\lambda=3$, and a new peak around $28^{\circ}$ shows up when $\lambda$ is 5 . This implies a significant change in the structures of the composites with large strain. The crystallinity index CI and the average crystallite size $L_{120}$ (taking 120 plane as an example) were calculated according to the data in Fig. 7 using eqn (5) and (6); $;^{42-45}$ then the results are found in Fig. 8.

$$
\begin{aligned}
& \mathrm{CI}=\frac{I_{\mathrm{c}}}{I_{\mathrm{c}}+I_{\mathrm{a}}} \times 100 \% \\
& L_{120}=\frac{k \lambda}{\frac{\beta_{1 / 2}}{57.3} \times \cos \theta}
\end{aligned}
$$

where $I_{\mathrm{c}}$ is the total integrated intensity of crystals (200 120 reflections were taken) and $I^{\mathrm{a}}$ is the total integrated intensity of amorphous peaks. $K$ is a constant value of $0.89 .^{43} \lambda$ is the wavelength $0.154 \mathrm{~nm} . \beta_{1 / 2}$ is the width at half-height of the 120 reflection, and $\theta$ is the Bragg angle (half of the scattering angle).

In Fig. 8(a), it can be seen that CI increases with increasing strain but decreases after adding $\mathrm{AE}$ into the composites, which can be noticed apparently at $\lambda=3$, in contrast to the system with no AE. This means that $\mathrm{AE}$ has a negative effect on the
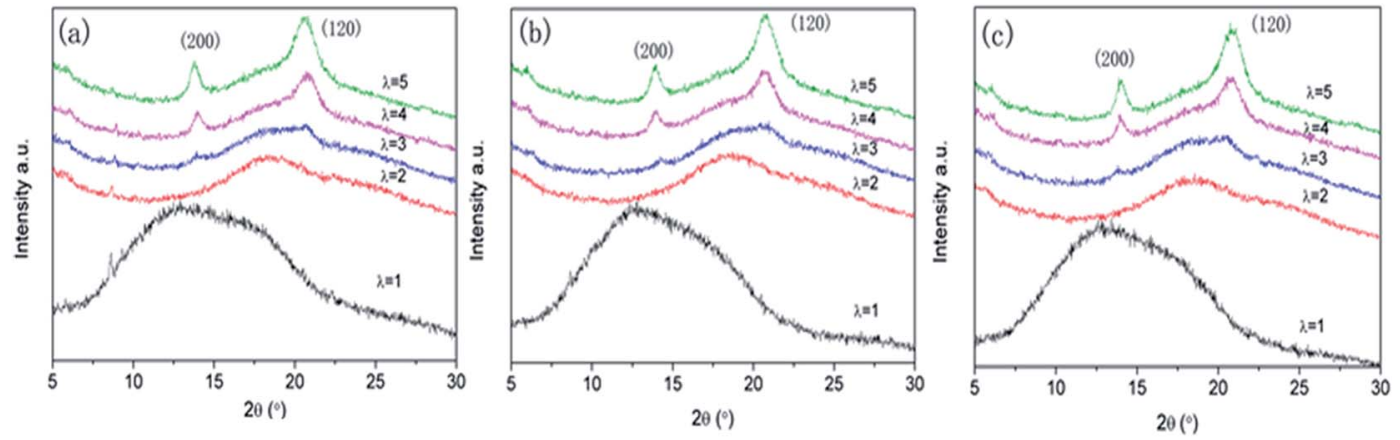

Fig. 6 XRD spectra of NR/CB composites under constant strains: (a) 0 phr AE, (b) 3 phr AE, (c) 5 phr AE (strain ratio, $\lambda=$ constant length/initial length).
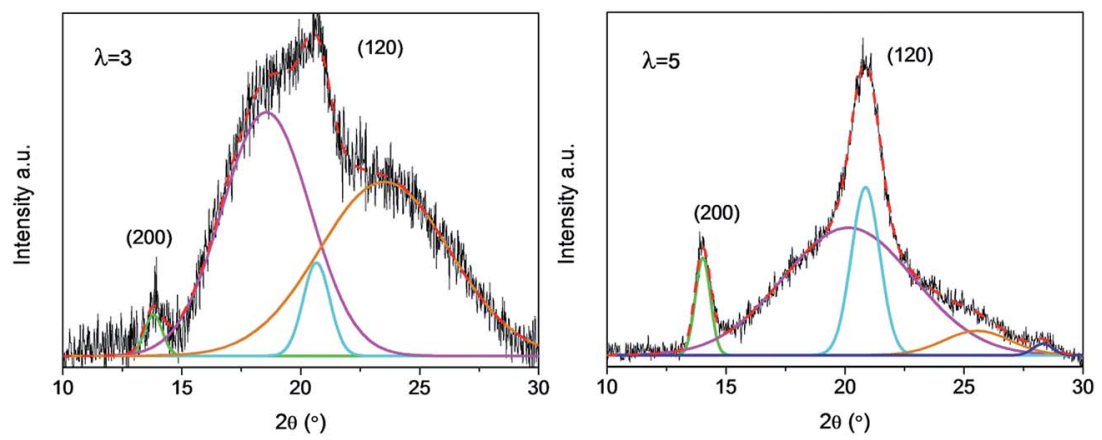

Fig. 7 XRD crystallization peak fitting of NR/CB composites without AE at different strain. 

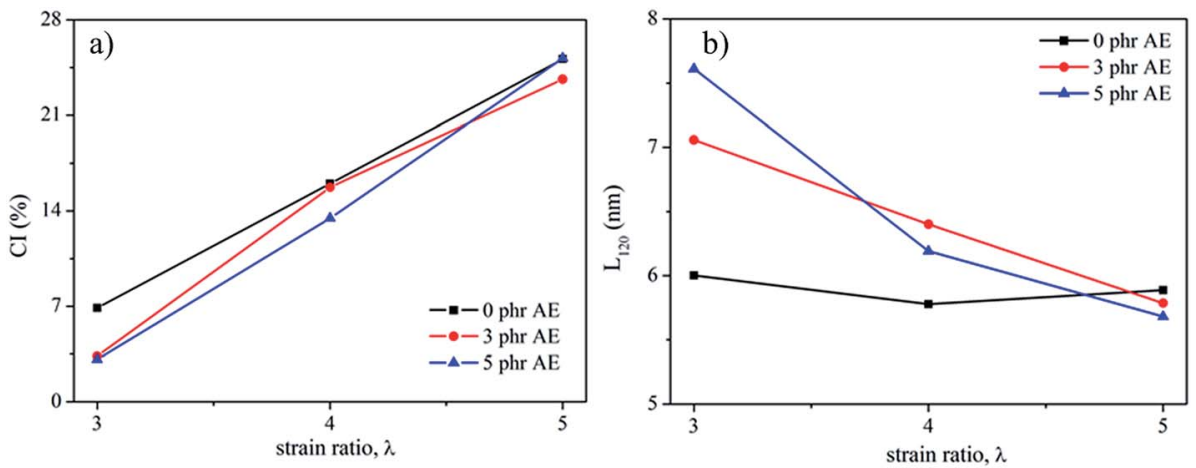

Fig. 8 Crystallization index (CI) (a) and lateral crystallite size, $L_{120}$, (b) of NR/CB composites with different AE.

crystallization behavior of NR/CB composites. However, in light of the difference in slopes, it can be seen that the composites with $\mathrm{AE}$ have large values of crystallization rate, $\mathrm{CR}$, with increasing strain, and CR becomes higher when $\mathrm{AE}$ is added at $5 \mathrm{phr}$ compared with that of $3 \mathrm{phr}$. Generally, straininduced crystallization SIC of natural rubber is influenced by stretching velocity, ${ }^{46}$ filler, ${ }^{43,45}$ additives, ${ }^{44,47}$ temperature, ${ }^{45}$ filler-rubber interaction and so on. In the composites, $\mathrm{AE}$ and filler-rubber interaction might be the dominant reasons for the variation of SIC behaviors. The increase in CR due to $\mathrm{AE}$ in composites should be because of the enhanced slipping effect of NR molecular chains that induce a growth of lattice size along the stretching direction; moreover, the weakened filler-rubber interaction improves the mobility of NR molecular chains, which is beneficial for crystallization. On the other hand, the slipping effect of NR molecular chains by AE might also collapse the chain-folded lamellae or sheaflike (fringed micelle) crystallites $^{43,45,48}$ and decrease the CI. According to the experimental results that CI decreased via adding $\mathrm{AE}$ at the same strain ratio, the later one might be primary. Another fact to interpret the decline of CI is the decrease of $L_{120}$ with increasing strain in NR/CB composites (Fig. 8(b)), which is in agreement with previous reports. ${ }^{42,43,49} \mathrm{It}$ can be observed that $L_{120}$ appears to slightly fluctuate in composites without AE with increasing strain, which indicates that the increase in crystallinity is because of the increased number of crystallites. ${ }^{41}$ However, $L_{120}$ is increased with the increase of $\mathrm{AE}$ at $\lambda=3$ and it decreases significantly on increasing the strain. The greater the content of $\mathrm{AE}$, the larger is the value of the slope of the curve. The increase of $L_{120}$ by $\mathrm{AE}$ at low strain should be related to the unrestricted rubber chains. The new generated crystallites can be compressed ${ }^{44}$ easily while stretching for the weakened filler-rubber interaction, due to which the stress is focused on the rubber chain. Then, lateral size of composites $L_{120}$ is decreased sharply.

\section{Effects of AE on mechanical properties of NR/CB composites}

Table 3 compares the impact of different $\mathrm{AE}$ on the mechanical properties of NR/CB composites. It can be seen that $100 \%$ modulus is increased by adding $\mathrm{AE}$, and the maximum value is obtained when loading $\mathrm{AE}$ at 1 phr. 300\% modulus of composites appears to be a decreasing tendency when $\mathrm{AE}$ exceeds $1 \mathrm{phr}$ and the values are lower than that of blank sample without AE. The increase of $100 \%$ modulus should be caused by the augment of physical entanglement points that made a positive effect on CB-NR interaction. On the other hand, the decrease of dispersive free energy on the CB surface caused by $\mathrm{AE}$ would take a dominant position compared with the entanglement effect at large strain, such as $300 \%$ elongation, where entanglement points could be destroyed, resulting in the reduction of $\mathrm{CB}-\mathrm{NR}$ interaction. This is the reason for the decline of $300 \%$ modulus. Simultaneously, tear strength is increased with the increase of $\mathrm{AE}$ until it reaches a threshold value at $2 \mathrm{phr} \mathrm{AE}$, and a degressive trend shows up for the value of elongation at break. However, there is no significantly disciplinary change on tensile strength on increasing $\mathrm{AE}$. Generally, the optimal content of $\mathrm{AE}$ for $\mathrm{NR} / \mathrm{CB}$ composites is 2 phr.

Table 3 Mechanical properties of NR/CB composites modified by AE

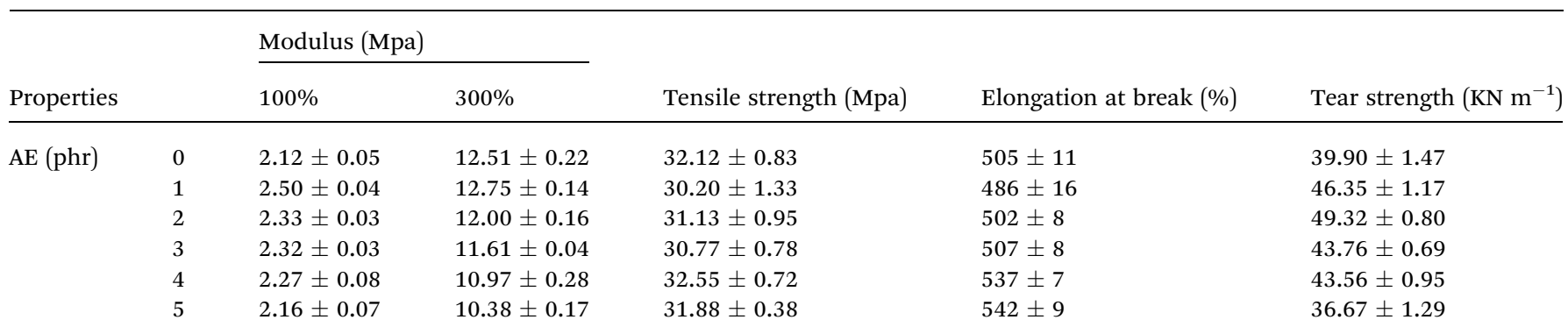




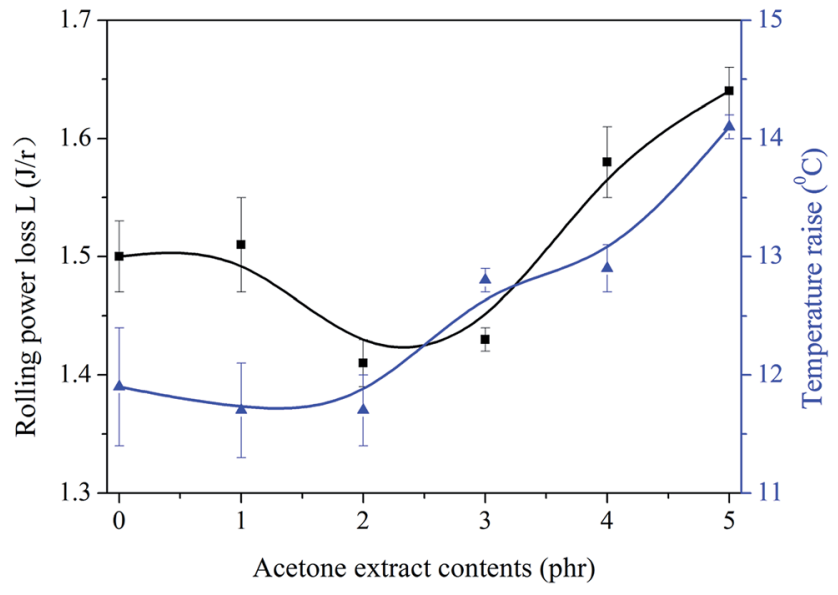

Fig. 9 Influence of $\mathrm{AE}$ on rolling power loss and temperature raise of NR/CB composites.

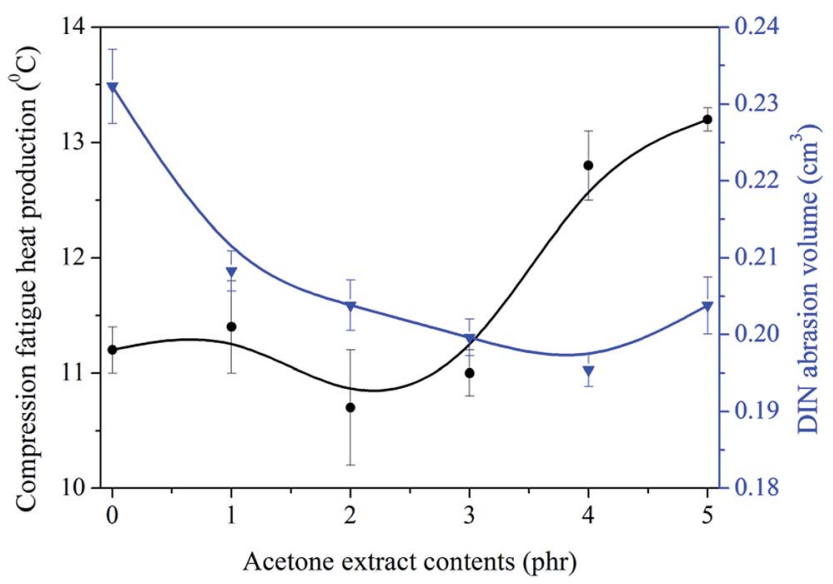

Fig. 10 Influence of AE on compression heat production and abrasion resistance of NR/CB composites.

\section{Effects of AE on dynamical properties of $\mathrm{NR} / \mathrm{CB}$ composites}

Rolling power loss, $L$, and temperature raise of $\mathrm{NR} / \mathrm{CB}$ composites were investigated and the results are shown in Fig. 9. It can be seen that $L$ is decreased firstly while increasing $\mathrm{AE}$ until it gets the minimum value at $\mathrm{AE}$ of $2 \mathrm{phr}$. With the increase of $\mathrm{AE}$, temperature raise also decreases slightly until it obtains a threshold value at $\mathrm{AE}$ is $2 \mathrm{phr}$. Therefore, the optimized ratio for $\mathrm{AE}$ in NR/CB composites is $2 \mathrm{phr}$. The increase of $L$ and the temperature raise should be caused by the weakened CB-rubber interaction. The increase of entanglement points might be responsible for the slight decrease of $L$ and temperature raise, which has a positive effect on $\mathrm{CB}$-rubber interaction and a negative influence on $\mathrm{CB}-\mathrm{CB}$ interaction.

Compression fatigue heat production and DIN abrasion volume were characterized, and the results are shown in Fig. 10. It is observed that heat production decreases slightly with the increase of $\mathrm{AE}$ until it achieves a threshold value at AE of 2 phr. This is correlated well with the results in Fig. 9. DIN abrasion volume is significantly decreased on increasing $\mathrm{AE}$ and it obtains its minimum value when $\mathrm{AE}$ is $4 \mathrm{phr}$. Although a decline in DIN abrasion volume is seen, the difference is not significant. Generally, the optimized ratio of $\mathrm{AE}$ is 2 phr.

Above all, two ambivalent aspects influenced the CBrubber interaction. One is the positive effect of $\mathrm{AE}$ on the formation of entanglement points, which improved the CBrubber interaction. The other is the decrease of dispersive free energy $\left(\gamma_{\mathrm{s}}^{\mathrm{d}}\right)$ on the CB surface via adding AE that reduced the CB-rubber interaction. The latter should be the dominant factor when the content of $\mathrm{AE}$ exceeded $2 \mathrm{phr}$ where the optimal dynamic properties of NR/CB composites were obtained. The mechanism of CB-rubber interactions are shown in Fig. 11.

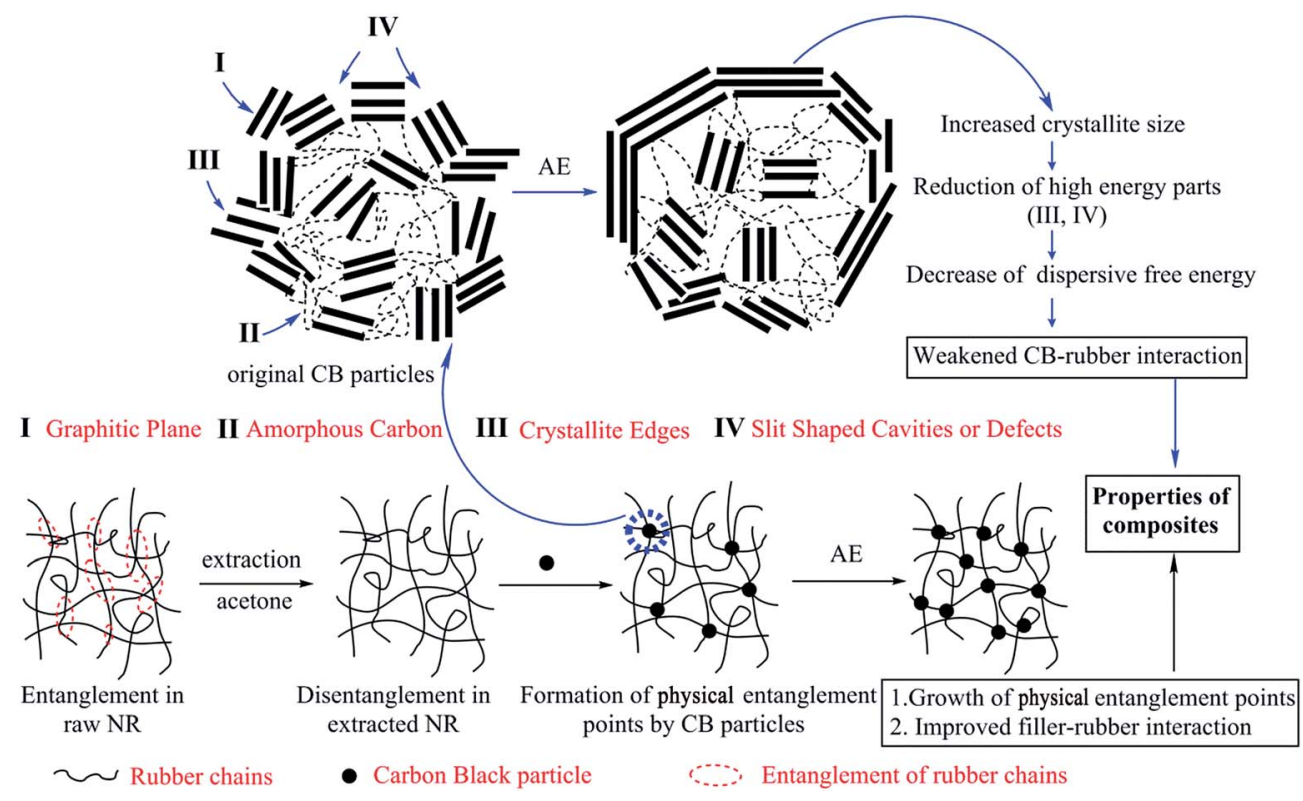

Fig. 11 Mechanism of $C B$-rubber interaction influenced by $A E$. 


\section{Conclusions}

In summary, the influence of acetone extract (AE) from natural rubber on the interface structure and mechanical properties of NR/CB composites were investigated. Raman spectrum and $\mathrm{XRD}$ representation illustrated that crystallite size of $\mathrm{CB}$ was increased in NR matrix, and it became a larger value when $\mathrm{AE}$ was added. The result induced a decrease of the dispersive free energy $\left(\gamma_{s}^{d}\right)$ on CB surface, which led to the reduction of CB-NR interaction. These phenomena were also proven by the decrease of constrained regions of NR/CB composites. Simultaneously, $\mathrm{AE}$ could improve the contact between $\mathrm{CB}$ and $\mathrm{NR}$ that increased the number of entanglement points and resulted in the promotion of $\mathrm{CB}-\mathrm{NR}$ interaction. The two contradictory aspects affected the application properties of NR/CB composites. Generally, the optimized content of AE in NR/CB composites is $2 \mathrm{phr}$ where the optimal mechanical and dynamical properties are obtained. On the other hand, AE might affect the strain-induced crystallization behaviors of NR/CB composites by decreasing the crystallization index (CI). Our study clearly disclosed the relationship between $\mathrm{AE}$ and structural variation or application performance of NR/CB composites firstly, which is useful to the improvement of theoretical research for NR. It might also make sense to the cultivation of Hevea brasiliensis concerning the content of $\mathrm{AE}$, or how to control an appropriate content of AE to meet the needs of the market. Simultaneously, the reduction of rolling resistance of $\mathrm{NR} / \mathrm{CB}$ composites when $\mathrm{AE}$ was added at $2 \mathrm{phr}$ is very valuable to the development of green tyres, which could significantly decrease atmospheric pollution.

\section{Acknowledgements}

The authors thank the financial support from the National Basic Research Program of China, Grant No. 2015CB654700 (2015CB674703), Special Fund for Agro-scientific Research in the Public Interest from the Ministry of Agriculture, China (201403066) and National Key Technology R \& D Program of China (2012BAE01B03).

\section{References}

1 S. Rolere, S. Liengprayoon, L. Vaysse, J. Sainte-Beuve and F. Bonfils, Polym. Test., 2015, 43, 83-93.

2 A. Nimpaiboon, S. Amnuaypornsri and J. Sakdapipanich, Polym. Test., 2013, 32, 1135-1144.

3 E. Ehabé, F. Bonfils, C. Aymard, A. K. Akinlabi and J. S. Beuve, Polym. Test., 2005, 24, 620-627.

4 S. Toki, B. S. Hsiao, S. Amnuaypornsri and J. Sakdapipanich, Polymer, 2009, 50, 2142-2148.

5 A. Nimpaiboon and J. Sakdapipanich, Polym. Test., 2013, 32, 1408-1416.

6 R. F. A. Altman, Ind. Eng. Chem., 2002, 40, 241-249.

7 T. Xu, Z. Jia, Y. Luo, D. Jia and P. Zheng, Appl. Surf. Sci., 2015, 328, 306-313.

8 U. Sookyung, C. Nakason, N. Venneman and W. Thaijaroend, Polym. Test., 2016, 54, 223-232.
9 B. Zhong, Z. Jia, Y. Luo, B. Guo and D. Jia, Composites, Part A, 2015, 73, 63-71.

10 H. Yingpin, Natural Rubber Processing, Hainan press, Haikou, 2007.

11 B. Wang, The effects of the Properties of Nature Rubber after Ozone Aging under different Production Processes and Components, Hainan University, 2015.

12 L. Ma, Extraction and Analysis of Acetone Extract from Natural Latex and its Effects on Properties of Rubber, Hainan University, 2011.

13 L. Fan, Extraction and Analysis of Water-soluble Substance in Natural Rubber Latex and its Effects on Properties of Natural Rubber, Hainan University, 2013.

14 W. Thongruang, B. Nooklay, P. Bunnaul, R. J. Spontak, P. Smithmaitrie and K. Chetpattananondh, Adv. Mater. Res., 2013, 844, 309-313.

15 H. Xu, J. Han, F. Liang, X. Zhang and C. Wu, Acta Polym. Sin., 2007, 007, 785-789.

16 W. Wongsorat, N. Suppakarn and K. Jarukumjorn, Adv. Mater. Res., 2011, 264-265, 646-651.

17 H. Ismail, S. Z. Salleh and Z. Ahmad, J. Elastomers Plast., 2013, 45, 445-455.

18 D. Fragiadakis and P. Pissis, J. Non-Cryst. Solids, 2007, 353, 4344-4352.

19 A. Sargsyan, A. Tonoyan, S. Davtyan and C. Schick, Eur. Polym. J., 2007, 43, 3113-3127.

20 X. Zhang and L. S. Loo, Macromolecules, 2009, 42, 5196-5207.

21 Y. Miwa, A. R. Drews and S. Schlick, Macromolecules, 2006, 39, 3304-3311.

22 B. Zhong, Z. Jia, Y. Luo and D. Jia, Compos. Sci. Technol., 2015, 117, 46-53.

23 J. Mijović, H. K. Lee, J. Kenny and J. Mays, Macromolecules, 2006, 39, 2172-2182.

24 J. P. And and S. C. Jana, Macromolecules, 2003, 36, 83918397.

25 S. V. And and I. Dranca, J. Phys. Chem. B, 2004, 108, 1198111987.

26 T. Jawhari, A. Roid and J. Casado, Carbon, 1995, 33, 15611565.

27 Y. R. Smith, D. Bhattacharyya, T. Willhard and M. Misra, Chem. Eng. J., 2016, 296, 102-111.

28 M. Pawlyta, J. N. Rouzaud and S. Duber, Carbon, 2015, 84, 479-490.

29 P. Lespade, A. Marchand, M. Couzi and F. Cruege, Carbon, 1984, 22, 375-385.

30 J. Robertson, Adv. Phys., 1986, 35, 317-374.

31 W. Zhu, D. E. Miser, W. G. Chan and M. R. Hajaligol, Carbon, 2004, 42, 1841-1845.

32 S. Zhang, L. Wei, H. Gu and Y. Zhu, J. Mater. Sci. Eng., 2006, 24, 337-340.

33 B. E. Warren, J. Chem. Phys., 1934, 2, 551-555.

34 J. Biscoe and B. E. Warren, J. Appl. Phys., 1942, 13, 364-371.

35 L. Lu, V. Sahajwalla, C. Kong and D. Harris, Carbon, 2001, 39, 1821-1833.

36 C. R. Houska and B. E. Warren, J. Appl. Phys., 1955, 25, 15031509. 
37 H. Darmstadt, C. Roy, S. Kaliaguine, G. Xu, M. Auger, A. Tuel and V. Ramaswamy, Carbon, 2000, 38, 1279-1287.

38 P. Kowalczyk, K. Kaneko and A. P. Terzyk, Carbon, 2004, 42, 1813-1823.

39 A. Schröder, M. Klüppel, R. H. Schuster and J. Heidberg, Carbon, 2002, 40, 207-210.

40 J. B. Donnet, E. Custodéro, T. K. Wang and G. Hennebert, Carbon, 2002, 40, 163-167.

41 M. Tosaka, Strain-Induced Crystallization of Crosslinked Natural Rubber As Revealed by X-ray Diffraction Using Synchrotron Radiation, Peabody Museum, 2007.

42 L. Qu, G. Huang, Y. Nie, J. Wu, G. Weng and P. Zhang, J. Appl. Polym. Sci., 2011, 120, 1346-1354.

43 S. Poompradub, M. Tosaka, S. Kohjiya, Y. Ikeda, S. Toki, I. Sics and B. S. Hsiao, J. Appl. Phys., 2005, 97, 103521103529.
44 Y. Ikeda, Y. Yasuda, K. Hijikata, M. Tosaka and S. Kohjiya, Macromolecules, 2008, 41, 5876-5884.

45 N. Candau, L. Chazeau, J. M. Chenal, C. Gauthier and E. Munch, Compos. Sci. Technol., 2015, 108, 9-15.

46 N. Candau, L. Chazeau, J. M. Chenal, C. Gauthier, J. Ferreira, E. Munch and C. Rochas, Polymer, 2012, 53, 2540-2543.

47 C. T. Schrijvers, K. Stronks, H. D. V. D. Mheen and J. P. Mackenbach, Polymer, 2007, 48, 3801-3808.

48 F. Billmeyer Jr, Textbook of Polymer Science, Wiley, 3rd edn, 1984.

49 M. Tosaka, S. Murakami, S. Poompradub, S. Kohjiya, Y. Ikeda, S. Toki, I. Sics and B. S. Hsiao, Macromolecules, 2004, 37, 3299-3309. 